\title{
Designing a software for electronically computation teachers' performance
}

\author{
Z. Lashgari ${ }^{1}, \underline{\text {. Jourabchi }}^{2}$
}

\begin{abstract}
${ }^{1}$ Islamic Azad University of Qazvin, Deputy of Health, Qazvin University of Medical Sciences, Qazvin, Iran
${ }^{2}$ Department of Midwifery and Maternal and Child Health, Faculty of Nursing and Midwifery, Qazvin University of Medical and Health Sciences, Qazvin, Iran

Corresponding Address: Zinat Jourabchi, Qazvin University of Medical Sciences, Shahid Bahonar Blvd., Qazvin, Iran Tel: +98-28-33237268, Email: zjourabchi@qums.ac.ir
\end{abstract}

Received: 23 Jan 2017; Accepted: 29 May 2017

\section{* Abstract}

Background: Calculating the performance of instructors always requires time, effort, expense, and precision. Therefore, the use of information technology adds speed and precision.

Objective: This study aimed to provide an application for calculating the performance of instructors.

Methods: This experimental study conducted during 2010-14 in faculty of nursing and midwifery of Qazvin University. Based on the existing educational information of the school, first the programs was designed by Excel software, and then the amount of instructors units were calculated and compared in the course of five semesters. In the next two semesters, variables, forms and the process of calculation were developed.

Findings: The results showed that the knowledge of all faculty members over the course of five semesters, which was calculated using traditional and electronic methods. During the next two semesters, the program's problems were corrected and a computational program was prepared based on the objectives of the study.

Conclusion: The electronic calculation program calculates the performance of the instructors accurately and quickly.

Keywords: Technology, Electronic computing, Teachers’ performance

Citation: Lashgari Z, Jourabchi Z. Designing a software for electronically computation teachers' performance. J Qazvin Univ Med Sci 2018; 21 (6): 90-96. 


\title{
طراحى برنامه محاسبه الكترونيكى عملكرد مدرسين دانشكده پرستارى و مامايى قزوين
}

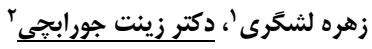

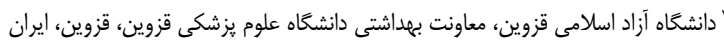

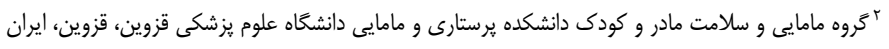

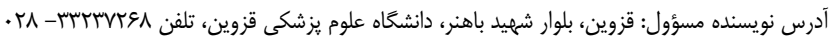

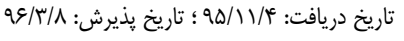

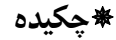

زمينه: محاسبه عملكرد اعضاى هيئت علمى همواره نياز به صرف وقت، نيرو، هزينه و دقت زياد دارد. لذا استفاده از فناورى اطلاعـات بـر سـرعت و

دقت كار مىافزايد.

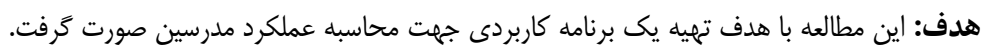

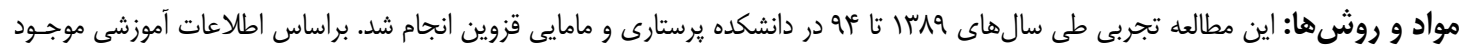

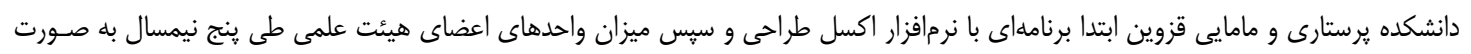

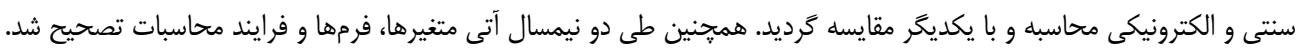

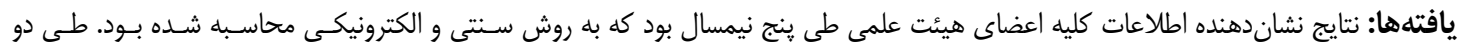

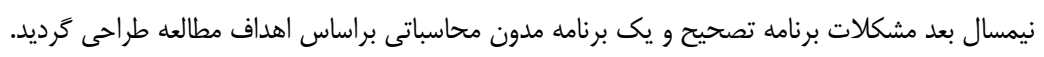

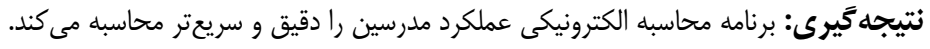

كليدوازهها: فناورى، محاسبات الكترونيك، عملكرد معلمين

(مقدمه:

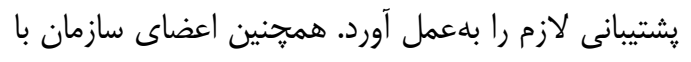

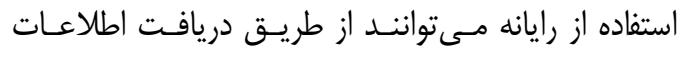

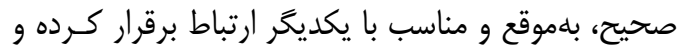

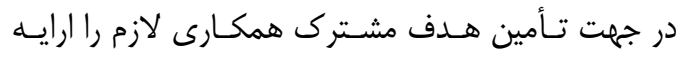

نمايند. به سادمى مـــــــان دريافت كـه فقـدان اطلاعـات

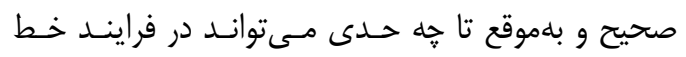

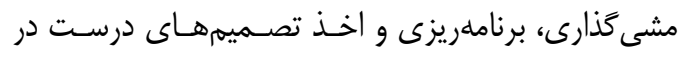

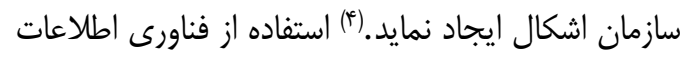

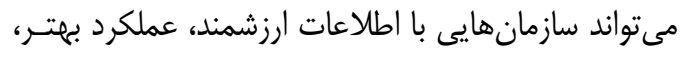

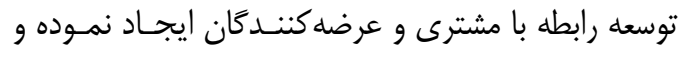

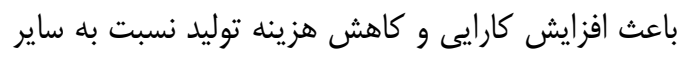

امروزه در عصرى بلهسر مىبريم كه فناورى اطلاعـات

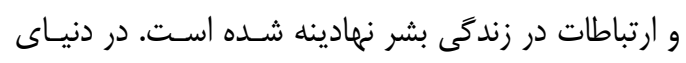

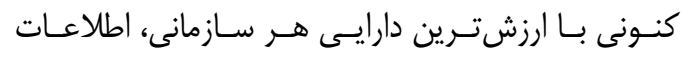

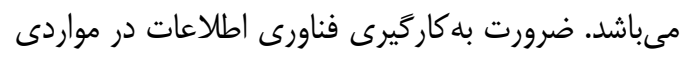

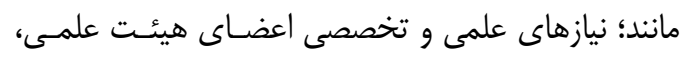

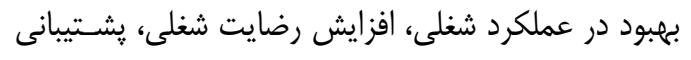

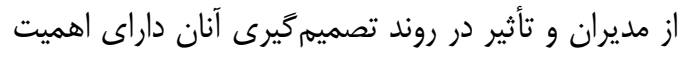

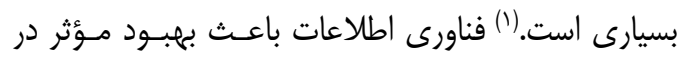

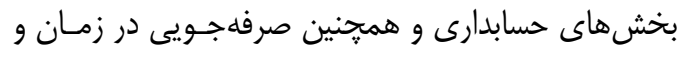

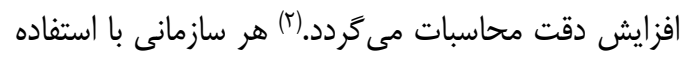

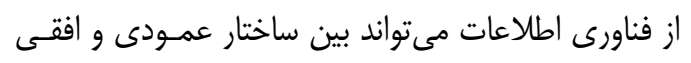

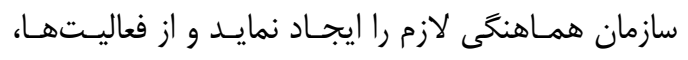


همان اطلاعات مربوط به تدريس اعضا هيئـت علمى در

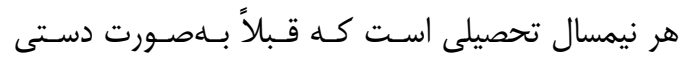

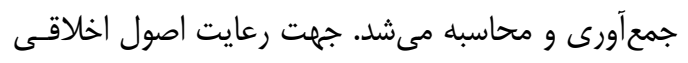

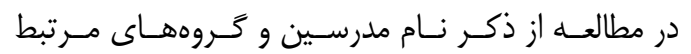
خوددارى شده است.

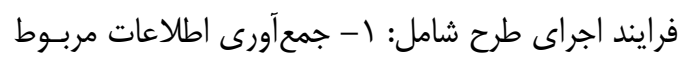

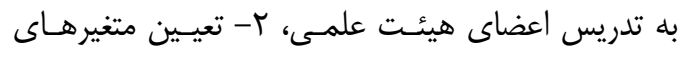

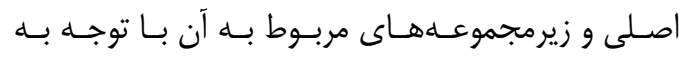

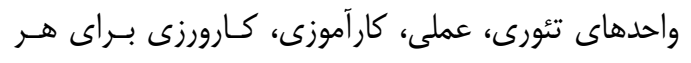

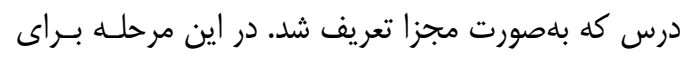
تهييه اطلاعات دقيق هر متغير فرمهاى خاصى تدوين شد.

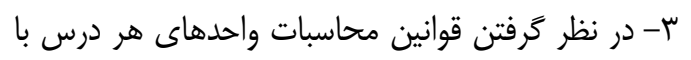
استفاده از نرمافزار ييشرفته اكسل و استانداردهاى حسابدار و اصول يذيرفته شده حسابدارى (FABS)

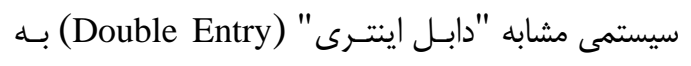

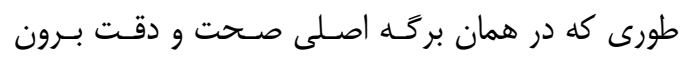

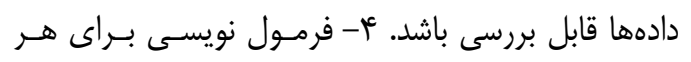

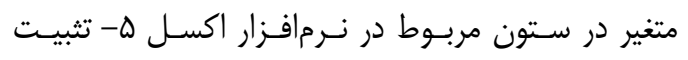

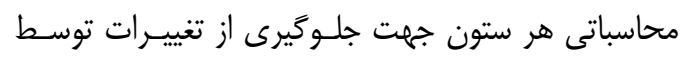

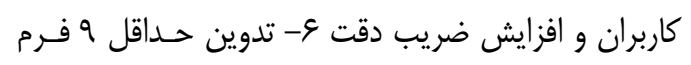

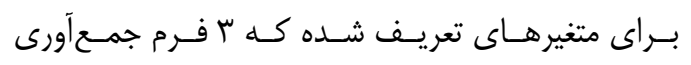

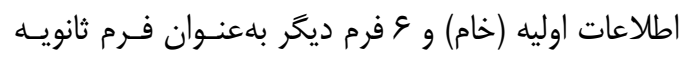
(محاسبه نهايى اطلاعات) بود.

شش فرم جهت محاسبه مجدد ميـزان واحـــ و ميـزان

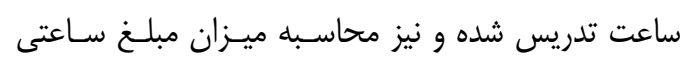

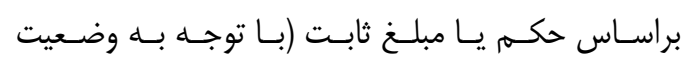

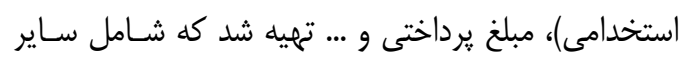

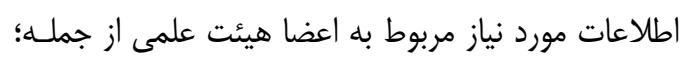

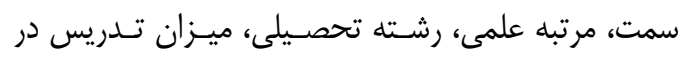

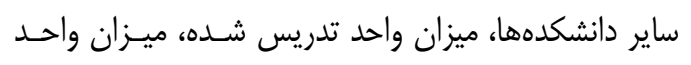

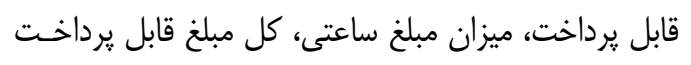

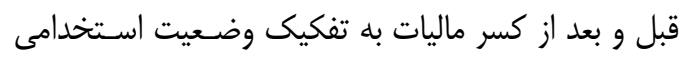

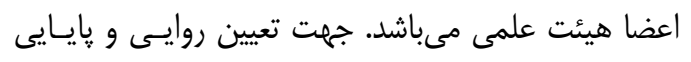
فرمهاى مذكور از نظرات مسئولين، اعضاى هيئت علمى و ولئي
سازمان ها شود.(ه) با توجه به ايـنـــه محاسـبه واحـدهاى

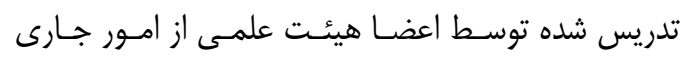

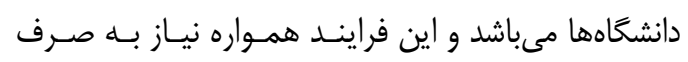

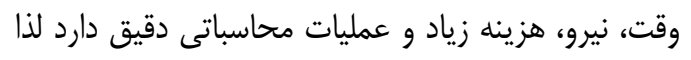

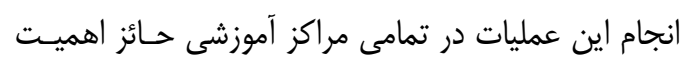

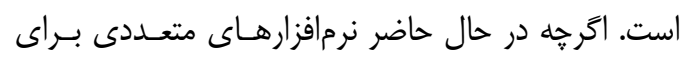
سنجش عملكـرد اعضـاى هيئـت علمسى وجـود دارد امـا

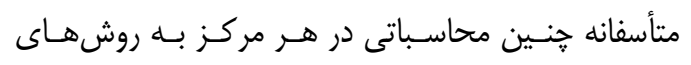

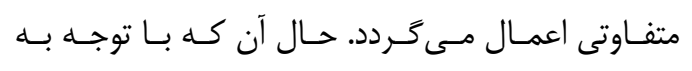
دستورالعمل محاسباتى واحدها بهخصوص در سطح وزارت

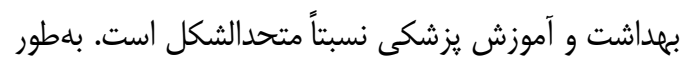
مثال واحدهاى مـوظفى براسـاس مرتبـه افـراد مسىبايسـد

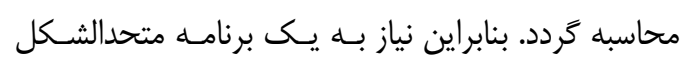
محسوس مىباشد. با برنامهريزى يكسان و استفاده از نرمافزارهاى موجود

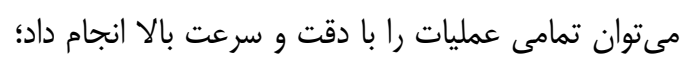

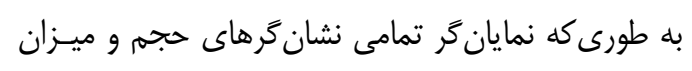

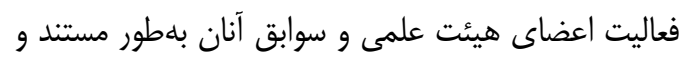

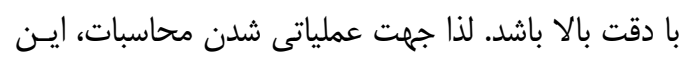

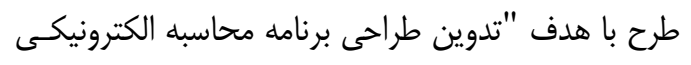

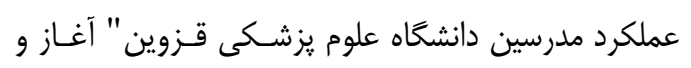

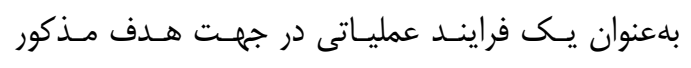
طراحى و در جند نيمسـال تحصـيلى مـورد ارزيسابى قـرار كرفت. - مرت

\section{إن مواد و روشها:}

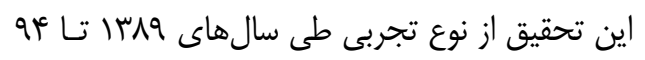

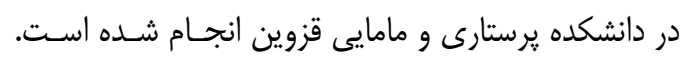

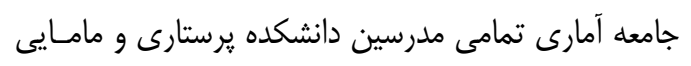

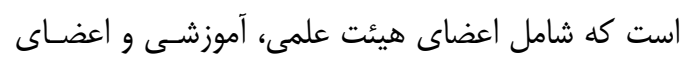

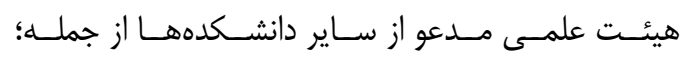

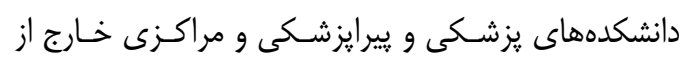

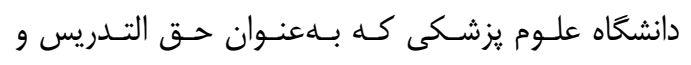

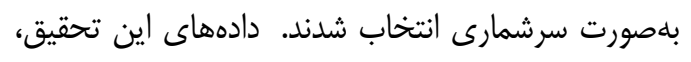


اطلاعات تدريس اعضاى هيئت علمى و آموزشى دانشكده

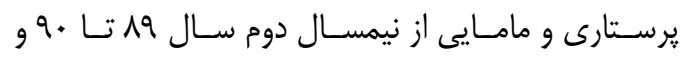

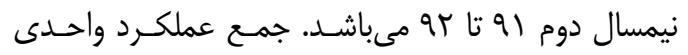

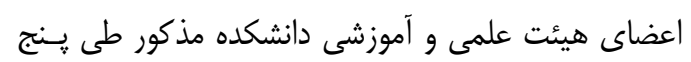

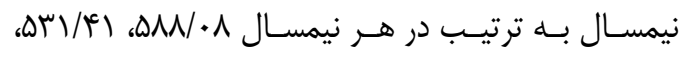

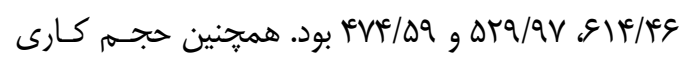

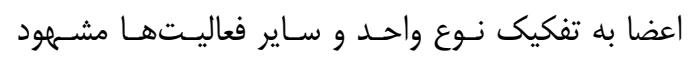

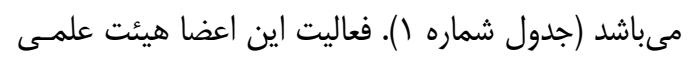

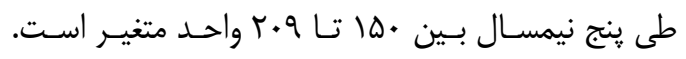

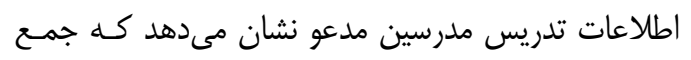

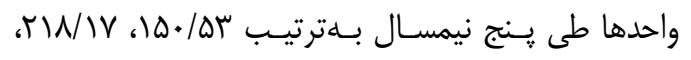

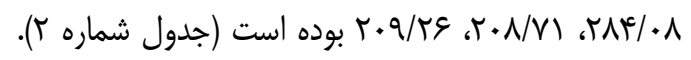

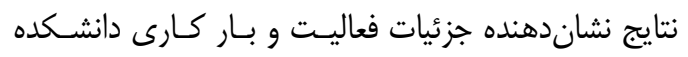
يرستارى و مامايى مىباشد.
كارشناسان مربوطه در مورد محتواى هر يك از فرمها اخذ

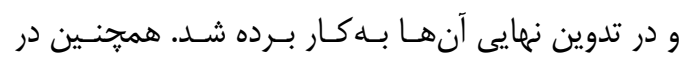
مرحله اول محاسبات دادههاى هر فرم طى يــنج نيمسـال

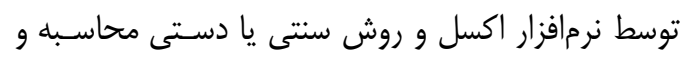

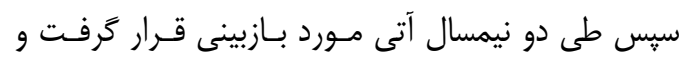

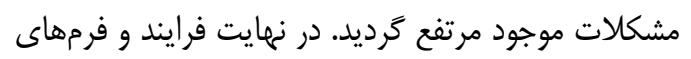
مربوط در نرمافزار اكسل نهايى و رمزخذارى شد مدرد

ميافتهها: مئن

متغيرهاى مورد استفاده جهت آناليز شامل؛ واحسدهاى

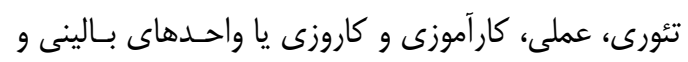
فعاليتهايى مانند: مشاوره دانشجويان، فعاليـت در مراكئ وارئز

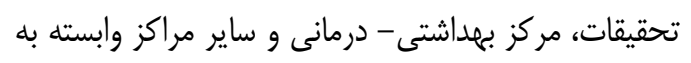

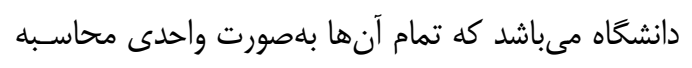

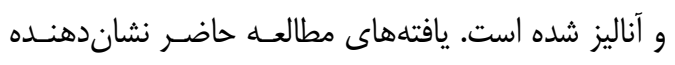

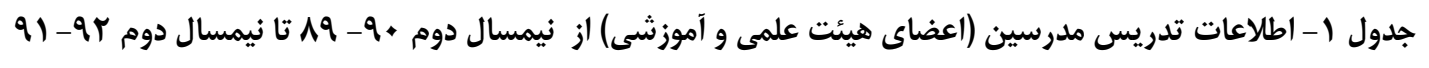

\begin{tabular}{|c|c|c|c|c|c|c|c|c|c|c|}
\hline \multicolumn{2}{|c|}{ دوم ا9 تا ז9 } & \multicolumn{2}{|c|}{ اول ا9 تا r9 } & \multicolumn{2}{|c|}{ دوم •9 تا 91} & \multicolumn{2}{|c|}{ اول •9 تا 91} & \multicolumn{2}{|c|}{ دوم 91 تا .9 } & \\
\hline درصد & ميزان & درصد & ميزان & درصد & مواحدان & درصد & واحدان & درصد & واحيز & \\
\hline II/ & $1.1 / 1 f$ & $\mid F / M$ & $V \Delta / / Q$ & $1 Q / T \pi$ & $q \Psi / \Delta F$ & $18 / v$. & $M N / V^{\top}$ & $\mid T / F V$ & $V \Psi / \% \Delta$ & تئورى \\
\hline$r / g \Gamma$ & $\mid r / 48$ & $r / 90$ & $r . / 90$ & $1 / \wedge$. & 111.9 & $r / N T$ & $1 F / E F$ & $\cdot / 19$ & $r / 91$ & عملى \\
\hline$V \cdot / 4 \Lambda$ & $r m / F 9$ & $v e / v q$ & ( & $W / \cdot F$ & 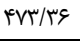 & $n+/ 19$ & $r q 4 / . V$ & $\vee \vee / \Delta \Lambda$ & $\mid \mathrm{FN} / \cdot \mathrm{t}$ & كار آموزى (بالينى) \\
\hline$\Delta / / Q$ & $r F / \Delta$ & $\Delta / \Delta V$ & $r q / \Delta$ & $r / 94$ & $r N / \Delta$ & $r / 9 r$ & re/IV & $8 / .9$ & $r \Delta / \Lambda$ & استاد مشاور \\
\hline . / T & $r$ & $1 / \Delta 1$ & $\wedge$ & $1 / \mu$. & $\wedge$ & $1 / \Delta \mid$ & $\wedge$ & $1 /{ }^{4}$ & $\wedge$ & ساير" \\
\hline $1 \cdots$ & $F v e / \Delta q$ & $1 \cdots$ & DTQ/qV & $1 \cdots$ & $9 \mid F / \uparrow 9$ & $1 \cdots$ & $\Delta H^{\prime} / F^{\prime}$ & $1 \cdots$ & $\Delta M / \cdot \Lambda$ & 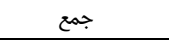 \\
\hline
\end{tabular}

\%اير واحدها شامل؛ فعاليت در مركز تحقيقات متابوليك، فعاليت در مركز بهداشتى - درمانى مينودر، مسئوليت EDO دانشكده و ... مىباشد.

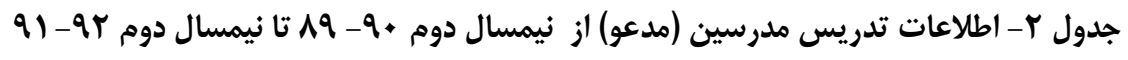

\begin{tabular}{|c|c|c|c|c|c|c|c|c|c|c|}
\hline \multicolumn{2}{|c|}{ دوم ا9 تا זq } & \multicolumn{2}{|c|}{ اول ا9 تا rو } & \multicolumn{2}{|c|}{ دوم •q تا (9) } & \multicolumn{2}{|c|}{ اول •q تا او } & \multicolumn{2}{|c|}{ دوم حه تا . } & \multirow[t]{2}{*}{ نيمسال } \\
\hline مرصد & مدعو & درصد & مدعو & درصد & مدعو & درصد & مدعو & درصد & مدعو & \\
\hline$r .1 .9$ & $F+/ F$ & $r / / q q$ & $9 \cdot|0|$ & $I T / M f$ & $r \Delta / \cdot \varphi$ & $1 Q / \Delta T$ & $r r / A V$ & Tr/NA & $r F / F$ & تئورى \\
\hline$F / \wedge f$ & $1 . / 14$ & $\Delta / \cdot \Delta$ & $1 . / \Delta F$ & $1 / n 1$ & $\varphi / \Lambda \varepsilon$ & $\Delta / / T$ & $11 / / V$ & r/१q & 8 & عملى \\
\hline$V \Delta / \cdot V$ & $\mid Q V / \cdot 9$ & $90 / 99$ & $\mid r V / 99$ & $\Lambda \Delta / १ \Delta$ & TFF/IG & $\mathrm{Vq} / \mathrm{rq}^{\prime}$ & $V \pi / / \pi$ & $V \pi / 19$ & $11 . / 1 \pi$ & كارآموزى (بالينى) \\
\hline $1 .$. & $r \cdot q / r q$ & $1 \ldots$ & $r \cdot N / V$ & $1 .$. & $r \Lambda F / \cdot \Lambda$ & $1 .$. & TIN/V & 1. & $10 \cdot / \Delta r$ & جمع \\
\hline
\end{tabular}


جهت تكميل رزومه و يا ارتقاى مدرسـين مـورد اسـتفاده

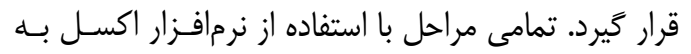

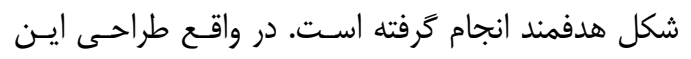

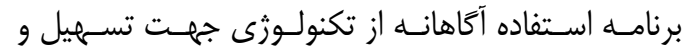

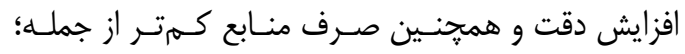

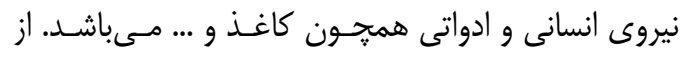

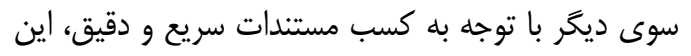

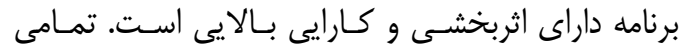

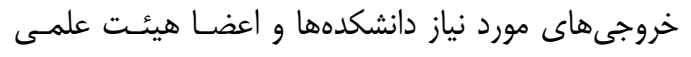
يس إز يكبار طراحى برنامه، تنها توسط يك ايراتور قابـل

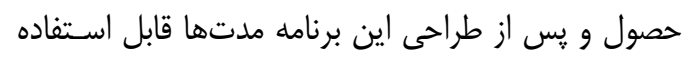

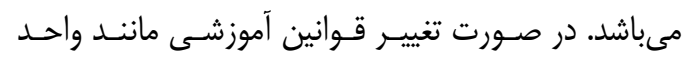

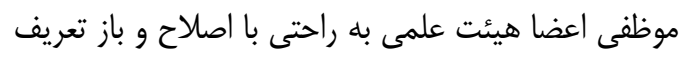

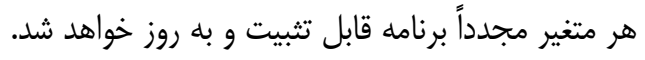
در بازبينى مطالعات در دسترس مطالعهاى همرراستا بـا بـا

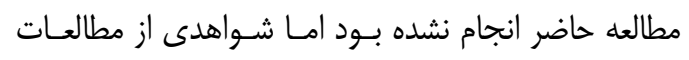

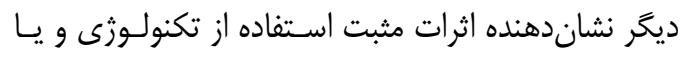

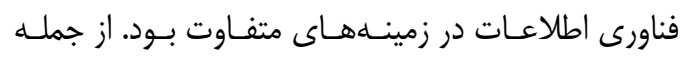

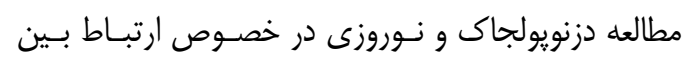

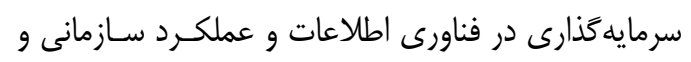

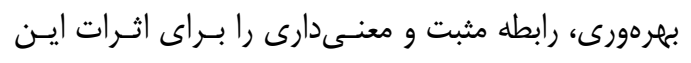

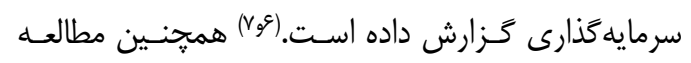

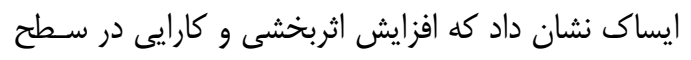

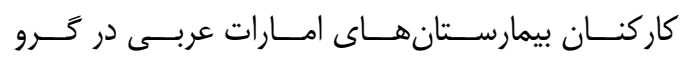

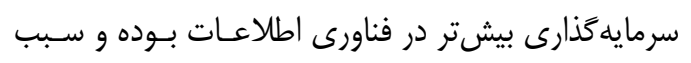
ارتقا مهارتهاى آنان مىشود.(^) مطالعه ديخرى در در ايتاليـا

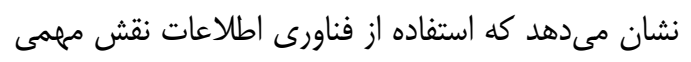

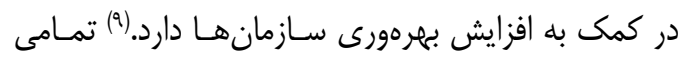

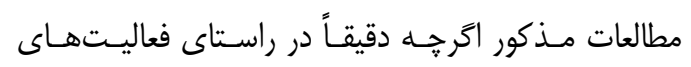
آموزشى و يا سازمانهاى دانشخاهى و آموزشى نمى باشند

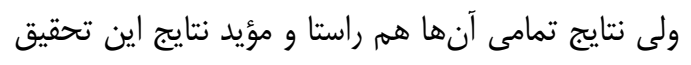

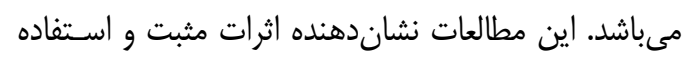

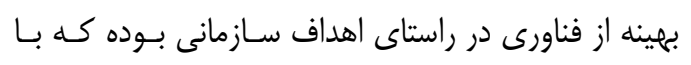

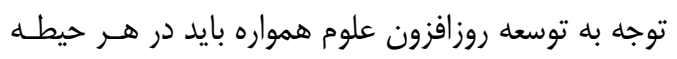

همجنين با توجه به محاسبات و روشهـاى اعمـال شـده

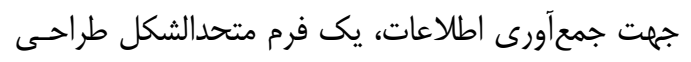

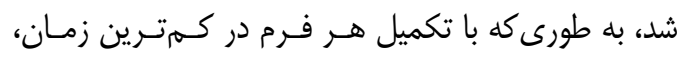
اطلاعات نيمسال هر فرد جمع آورى شود.

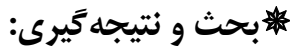

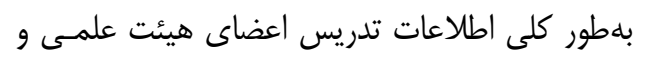

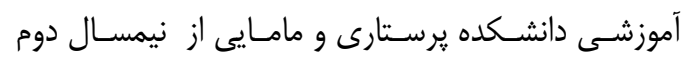

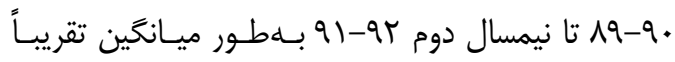

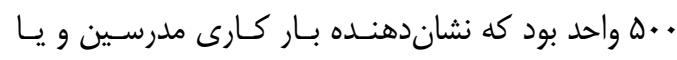
عملكرد آموزشى و اجرايى اعضا هيئـت علمى دانى دانشـكده

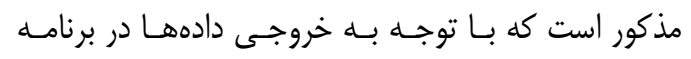

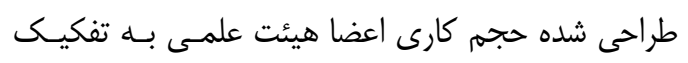

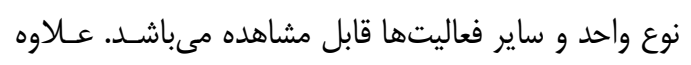

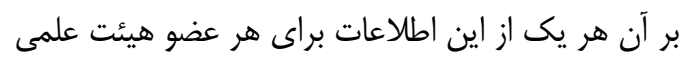

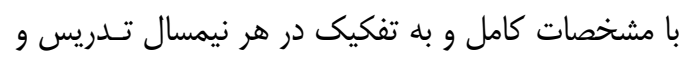

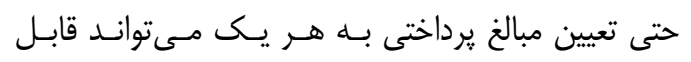

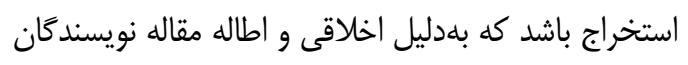

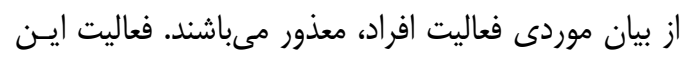

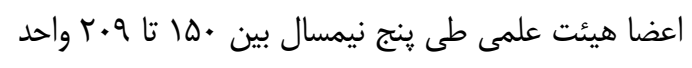

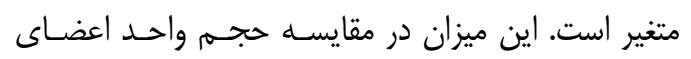
دانشكده بسيار كمتر است.

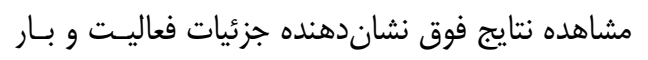

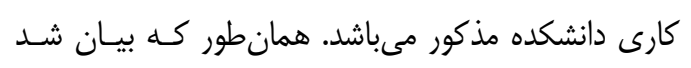

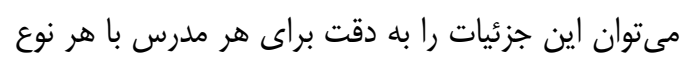

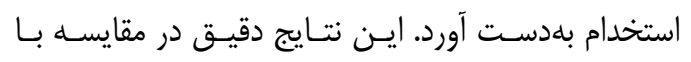

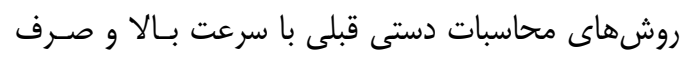

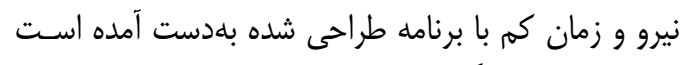

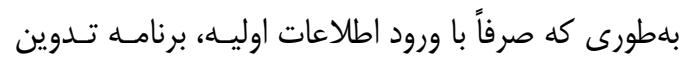

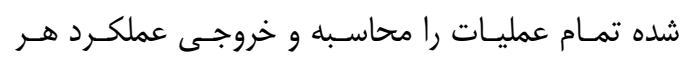
مدرس را در يك صفحه قابل خاض محاسبه مسىنمايســ از

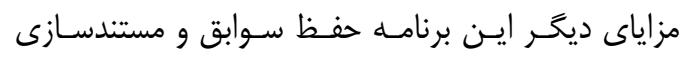
عملكرد اعضا هيئت علمى از شروع استفاده برنامـه، قابـل

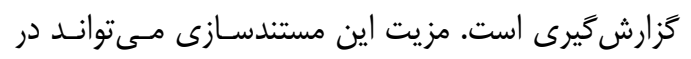




\section{: مراجع:}

1. Madadi Y, Manian A, Asgharzade E. An investigation of the role of information technology in the success of Educational organization. Iranian $\mathrm{J}$ Agricultural Economics Development Res 2011; 41-2(4): 413-23. [In Persian]

2. Jamei $\mathrm{R}$, Karamzadeh $\mathrm{T}$. The role of information technology (IT) in promotion of accrual accounting system in the medical science universities in Iran (Case Study: Kermanshah Medical Science University). J Empirical Res Accounting 2014; 4(1): 85-98. doi: 10.22051/jera.2015.1885. [In Persian] 3. Porter-O'Grady T, Malloch K. Leadership in nursing practice. Burlington: Jones \& Bartlett Publishers; 2015.

4. Cheburet SK, Odhiambo-Otieno GW. Process factors influencing data quality of routine health management information system: Case of Uasin Gishu County referral Hospital, Keny. Int Res J Public Environ Health 2016; 3(6): 132-9. doi: 10.15739/ irjpeh.16.017.

5. Hakansson $\mathrm{H}$, editor. Industrial technological development (Routledge Revivals): a network approach. New York: Routledge; 2015.

6. Noruzi MR, Rahimi GR. Multiple intelligences, a new look to organizational effectiveness. J Manag Res 2010; 2(2): 1-15.

7. Dženopoljac V, Janoševic S, Bontis N. Intellectual capital and financial performance in the Serbian ICT industry. J Intellectual Capital 2016; 17(2): 373-96. doi: 10.1108/ JIC-07-2015-0068.

8. Isaac JP. Comparing basic computer literacy self-assessment test and actual skills test in hospital employees. Available at:

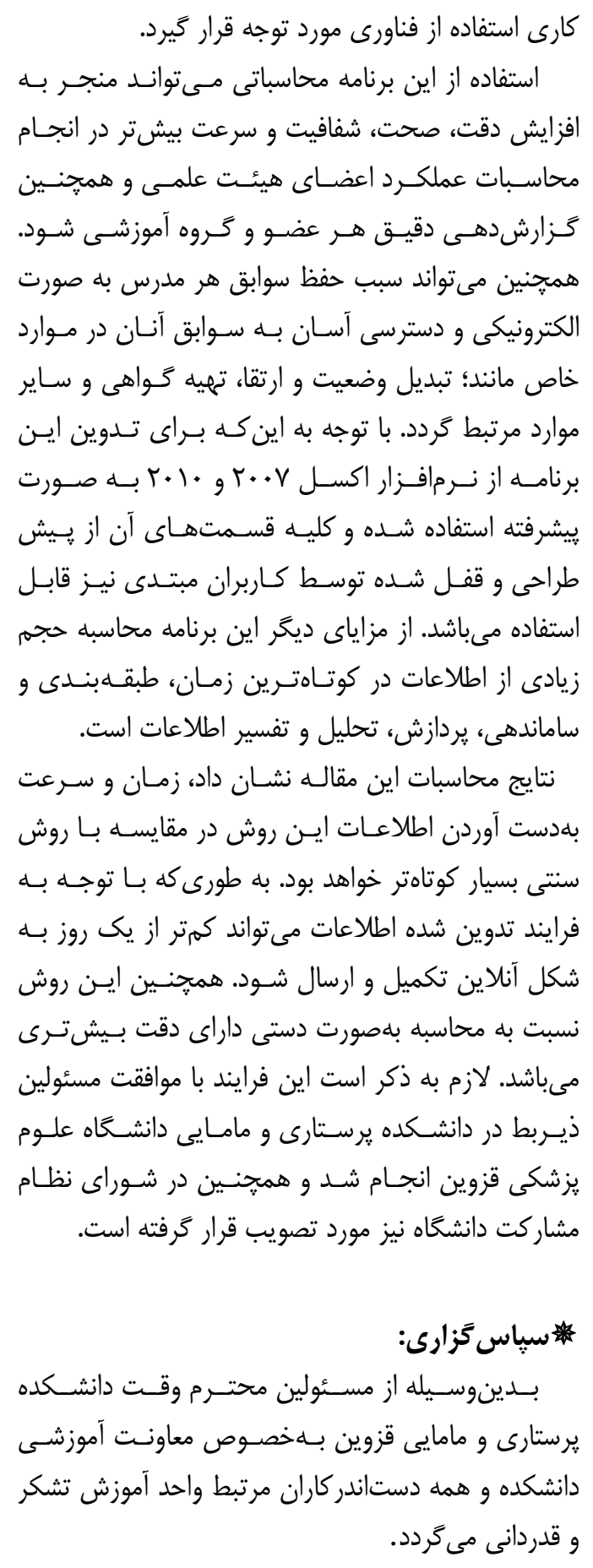


http://scholarworks.waldenu.edu/dissertations Accessed in: 2015.

9. Oh H, Johnson AL, Lucianetti L, Youn S. The effect of performance measurement systems on productive performance: an empirical study of Italian manufacturing firms. Available at SSRN: https://ssrn.com/abstract=2677354. Updated in: 2015 Oct 21. doi: 10.2139/ssrn.2677354. 